\title{
Colon inflammatory fibroid polyp in a patient with von Recklinghausen's disease: endoscopic aspect with narrow-band imaging and magnification
}
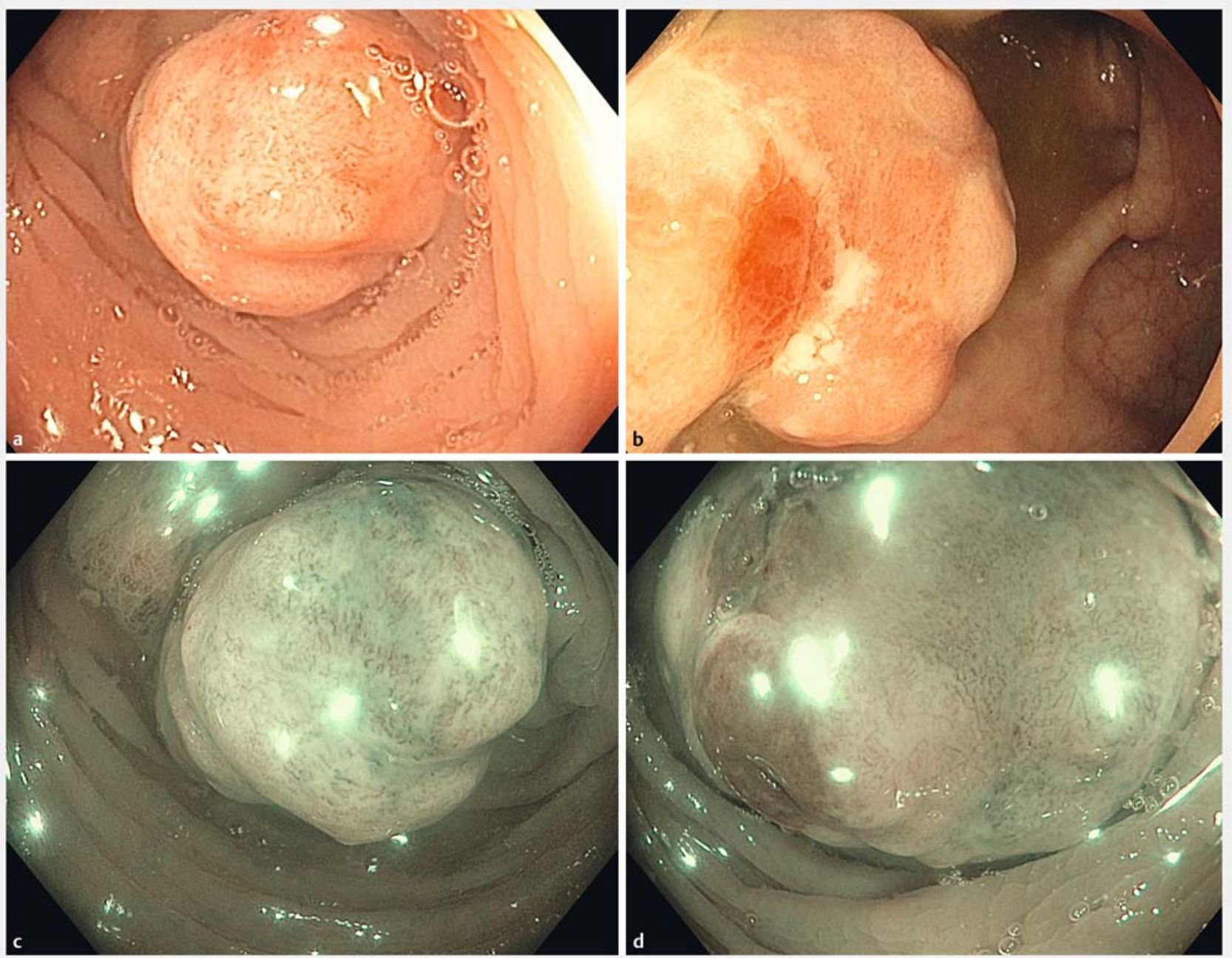

- Fig. 1 Endoscopic aspect of the inflammatory fibroid polyp. a Macroscopic aspect with white light. b Pedunculated shape. c Narrow-band imaging (NBI) aspect in far view, showing patchy avascular areas. $\mathbf{d}$ NBI in close-up view, showing irregular vessels.

The prevalence of gastrointestinal involvement in von Recklinghausen's disease is frequent $(11 \%-25 \%)$ [1] with different types of neurofibroma and juvenile-like polyps [2]. However, the association of von Recklinghausen's disease with inflammatory fibroid polyps has been only rarely described [3]. We report here the case of a 39-year-old woman with past history of type 1 neurofibromatosis who was referred for hematochezia.
Colonoscopy was performed and diagnosed a large pedunculated polyp in the sigmoid with a type Ip shape (Paris classification). Using narrow-band imaging and dual focus magnification (Olympus, Tokyo, Japan), the features of the polyp included an amorphous pit pattern over a large area (Kudo VN). The vascular pattern was patchy avascular areas mixed with large irregular vessels (Sano IIIB) (> Fig. 1, > Fig. 2, > Video 1). The vascular pattern was present over the whole lesion, without any demarcation line. Using the NICE classification [4], the lesion was classified as type III and was suggestive of a deep submucosal invasive cancer.

The lesion was resected en bloc by endoscopic mucosal resection with a large safety margin on the stalk. Pathological examination, after expert discussion (because of the atypical features), concluded a diagnosis of inflammatory fibroid polyp resected totally with safe margins, 

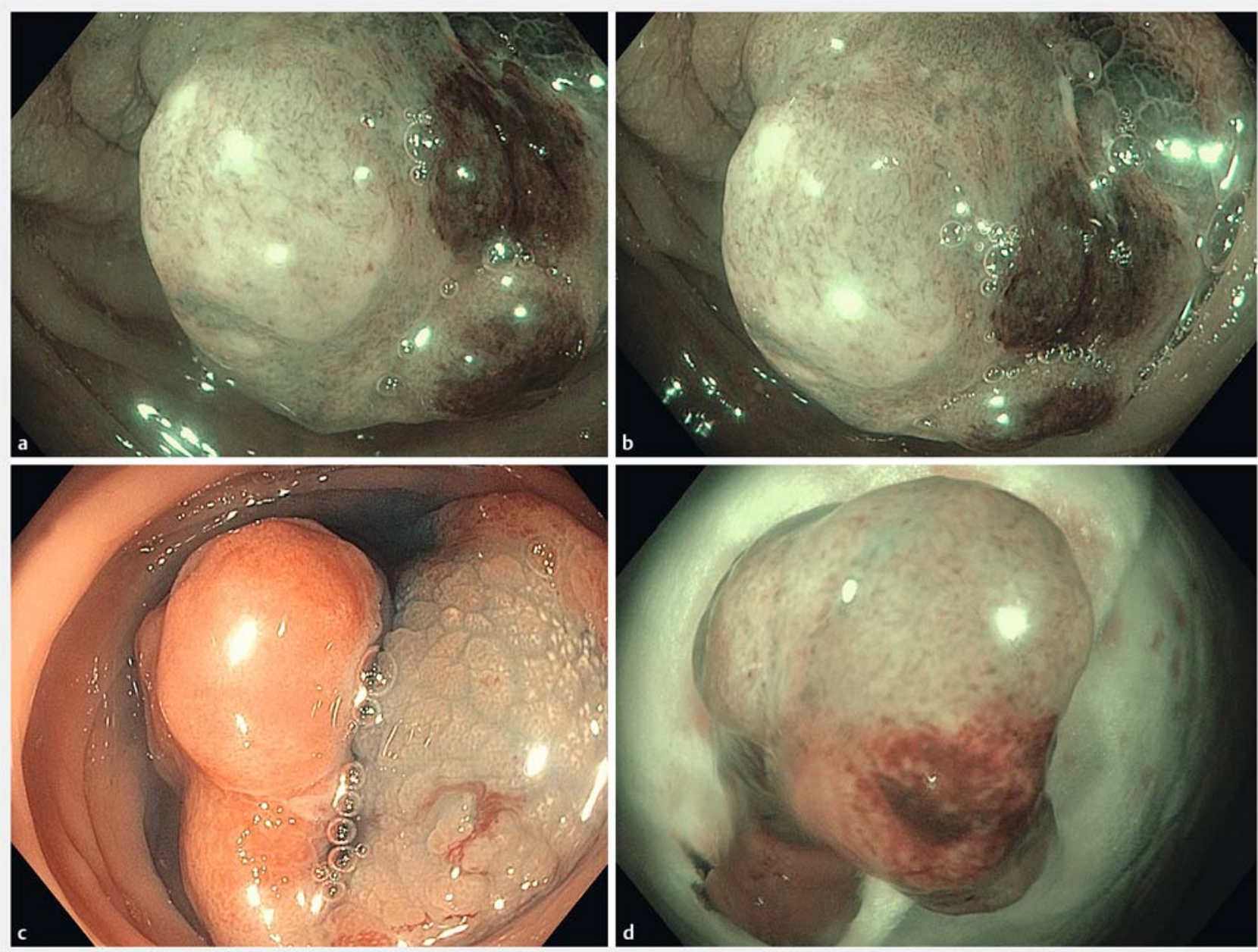

Fig. 2 Endoscopic aspect of the inflammatory fibroid polyp. a, b Avascular and amorphous whitish area. c Pedunculated aspect after injection. d Narrow-band imaging aspect of the resected specimen.

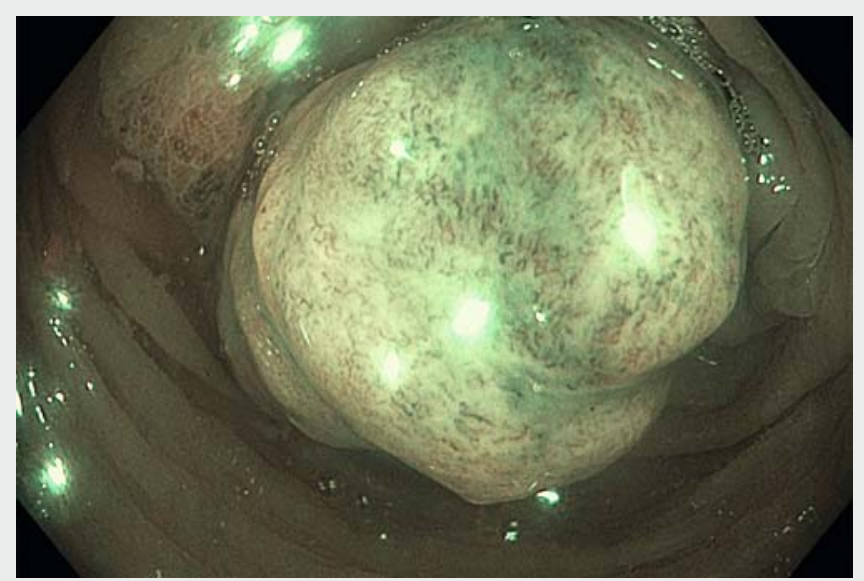

$\checkmark$ Video 1 Endoscopic aspect and resection of an inflammatory fibroid polyp. and not to a neurofibroma or a stromal tumor.

This case illustrates the lack of specificity of the invasive mucosal and vascular pattern of colorectal lesions, as has been demonstrated previously for inflammatory reactions after diverticulitis [5]. The lack of demarcation line, the pedunculated shape, and the past history of von Recklinghausen's disease may suggest the possibility of choosing endoscopic resection or biopsy sample instead of sending the patient for surgical management. Endoscopic resection with safe margins facilitates a precise pathological assessment to avoid the risk of incomplete resection and, as in the current case, unnecessary colectomy.

Endoscopy_UCTN_Code_CCL_1AD_2AC 
None

The authors

Julie Benard ${ }^{1}$, Jérôme Rivory ${ }^{1}$, Florian

Rostain ${ }^{1}$, Céline Montuclard ${ }^{2}$, Valérie

Hervieu $^{3}$, Thierry Ponchon ${ }^{1,4}$, Mathieu

Pioche $^{1,4}$

1 Department of Endoscopy and

Gastroenterology, Pavillon L, Edouard

Herriot Hospital, Hospices Civils de Lyon, Lyon, France

2 Department of Endoscopy and Gastroenterology, Valence Public Hospital, Valence, France

3 Department of Digestive Pathology, East University Hospitals, Lyon, France

4 Inserm U1032 LabTau, Lyon, France

\section{Corresponding author}

Mathieu Pioche, MD

Endoscopy Unit - Digestive Disease

Department, Pavillon L - Edouard Herriot

Hospital, 69437 Lyon Cedex, France

Fax: +33-4-72110147

mathieu.pioche@chu-lyon.fr

\section{References}

[1] Pinsk I, Dukhno O, Ovnat A et al. Gastrointestinal complications of von Recklinghausen's disease: two case reports and a review of the literature. Scand J Gastroenterol 2003; 38: 1275-1278

[2] Agaimy A, Schaefer I-M, Kotzina L et al. Juvenile-like (inflammatory/hyperplastic) mucosal polyps of the gastrointestinal tract in neurofibromatosis type 1 . Histopathology 2014; 64: 777-786

[3] Goto K, Hirosaki T, Masubuchi M. Neurofibromatosis Type 1-associated inflammatory polyp of the gastrointestinal tract. Int J Surg Pathol 2017; 25: 65-68

[4] Hayashi N, Tanaka S, Hewett DG et al. Endoscopic prediction of deep submucosal invasive carcinoma: validation of the narrowband imaging international colorectal endoscopic (NICE) classification. Gastrointest Endosc 2013; 78: 625-632

[5] Testu S, Morin C, Rivory J et al. A benign colorectal lesion with amorphous pit (Kudo $\mathrm{Vn}$ ) and avascular pattern (Sano's 3b): differential diagnosis with deep invasive adenocarcinoma. Endoscopy 2017; 49: E184E185

\section{Bibliography}

DOI https://doi.org/10.1055/s-0043-119983

Published online: 17.10 .2017

Endoscopy 2018; 50: E5-E7

(c) Georg Thieme Verlag KG

Stuttgart · New York

ISSN 0013-726X

\section{ENDOSCOPY E-VIDEOS}

https://eref.thieme.de/e-videos

回局 Endoscopy E-Videos is a free

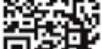
access online section, reporting G.: on interesting cases and new techniques in gastroenterological endoscopy. All papers include a high quality video and all contributions are freely accessible online.

This section has its own submission website at https://mc.manuscriptcentral.com/e-videos 